\title{
Dispositivo analítico para compreensão da leitura de diferentes tipos textuais: exemplos referentes à Física
}

\author{
M aria José P. M . deAlmei da*, Thirza Pavan Sorpreso*
}

Resumo: N esteartigo, articulamos noções que possibilitam a organização de um dispositivo analítico para compreensão deleituras dediferentes tipos deprodução. Tecemos considerações sobreessasnoções, apoiadasteoricamentena vertenteda análisedo discurso iniciada por $\mathrm{M}$ ichel Pêcheux, utilizando, principalmente, publicações realizadas no Brasil por Eni O rlandi. Com o intuito deevidenciar quenão selêda mesmamaneiraum livro didático, um texto dedivulgação científica ou um original de cientista, apresentamos exemplos referentes à Ciência, especificamenteà Física. Argumentamosqueessas leituras mobilizam diferentesinterdiscursos, mesmo que sejam realizadas por um mesmo indivíduo, pois supõem diferentesimaginários.

Palavras-chave: dispositivo analítico; análisedo discurso; Física.

Analytical device for reading comprehension of different kinds of texts: examples about Physics

Abstract: In thispaper, wearticulatenotionsthat enabletheorganization of an analytical device for reading comprehension of different types of productions. 0 ur considerations about these notions are based on discourse analysis from M ichael Pêcheux through Eni P. O rlandi publications in Brazil. Wepresent examples about Science, particularly Physics, in order to show that coursebooks, scientific popularization or scientists' original publicationsarenot read in the same way. Even if the readings are performed by the same individual, we argue that these readings mobilize different interdiscourses asthey assume different imaginary.

Key words: analytical device; discourseanalysis; Physics.

\section{Introdução}

N este texto circunstanciamos um dispositivo analítico pautado em noções da análise do discurso (AD ). Com ele objetivamos argumentar que não se lê da

* Professora titular do Departamento de Ensino e Práticas Culturais e coordenadora do grupo de estudo e pesquisa em Ciência e Ensino (gepCE) da Faculdade de Educação da U nicamp, Campinas, SP, Brasil. mjpma@ unicamp.br

** Doutoranda em Educação e membro do grupo de estudo e pesquisa em Ciência e Ensino (gepCE) da Faculdade de Educação da U nicamp, Campinas, SP, Brasil. thirza.ps@ gmail.com 
mesma maneira um livro didático, um texto de divulgação científica ou um original de cientista, pois essas leituras mobilizam diferentes interdiscursos, mesmo que sejam realizadas por um mesmo indivíduo, uma vez que supõem diferentes imaginários sobre sua produção. As noções da AD que explicitamos foram selecionadas a partir da vertente originada na França por $M$ ichel Pêcheux, nos pautando, principalmente, em publicações realizadas no Brasil por Eni O rlandi.

Circunstanciar um dispositivo dessa natureza justifica-se pelo fato de que, ao evidenciarmos que as interpretações possíveis na leitura de diferentes tipos textuais, tais como um livro didático, um texto de divulgação científica ou um texto original de cientista, mobilizam diferentes interdiscursos, estamos contribuindo para repensar o uso desses tipos textuais em situações de ensino.

D e imediato, lembramos as diferentes destinações das produções antes referidas e as maneiras como usualmente são utilizadas. Enquanto o livro didático é associado ao uso escolar, do básico ao superior, um texto de divulgação científica, embora possa ser utilizado na escola, não é produzido como um recurso a ela destinado. $E$, quanto a originais de cientistas, é fato que a sua leitura ocorre mais frequentemente no âmbito acadêmico. Podemos dizer que, na cotidianidade das pessoas, esses textos não funcionam da mesma maneira.

Agnes $\mathrm{H}$ eller possibilita-nos situar a noção de vida cotidiana. A autora afirma que "a vida cotidiana é a vida de todo o homem" (H eller 1985, p.17). Ele já nasce inserido na sua cotidianidade, e ninguém consegue desligar-se inteiramente dela, bem como não há nenhum homem que viva apenas na cotidianidade. A autora também alerta para o fato de que a manipulação das coisas, mesmo a mais elementar, está associada à assimilação de relações sociais, enquanto as formas de elevação acima da vida cotidiana que produzem obj eti vações duradouras são a arte e a ciência. Já a característica dominante da vida cotidiana é a espontaneidade.

Com base nessas noções, admitimos aqui que, quando pensamos na difusão de conhecimentos associados às chamadas Ciências da $\mathrm{N}$ atureza, é fato que um livro didático, um texto de divulgação ou um original de cientista, embora comportem relações tanto com a Ciência quanto com a vida cotidiana dos indivíduos, não o fazem da mesma maneira nem em igual proporção.

\section{Apoio teórico}

D issemos que a reflexão aqui apresentada se apoiava em noções da AD. Sobre a vertente em questão, destacamos a consideração da não transparência e da materialidade da língua. $E$ também que seu foco não é o estudo de funções da língua, mas sim 0 estudo do seu funcionamento. $\mathrm{N}$ a $A D$, considerado 0 
discurso como efeito de sentidos entre locutores, uma pergunta-chave é como determinado discurso foi construído.

Situada nessa vertente, O rlandi (1983, p. 22) caracteriza tipo e funcionamento do discurso, associando-os ao seu produto e ao seu processo de constituição:

[...] consideramos que o tipo (produto) é funcionamento discursivo (processo) que se cristaliza historicamente, dada a dinâmica das condições de produção. D essa forma, certas configurações se institucional izam esetornam típicas, constituindo, historicamente, model os para o funcionamento de qualquer discurso.

A autora assume que a leitura é produzida em determinadas condições de produção, que são as imediatas, mas também as sócio-históricas, e propõe considerá-la como o momento crítico de constituição do texto, o momento em que os interlocutores desencadeiam o processo de significação. 0 autor e 0 leitor em confronto "[...] definem-se em suas condições de produção e os fatores que constituem essas condições é que vão configurar o processo da leitura" (idem, p. 20). A relação necessária tanto com as condições imediatas (contexto da leitura) quanto com a exterioridade (condições sócio-históricas) é que evidenciam a incompletude do texto.

Q uanto às condições de produção da leitura, O rlandi (1984, p. 8) afirma que, na $A D:$ : [...] a leitura é vista como produzida em condições determinadas, ou seja, em condições sócio-históricas que devem ser levadas em conta". Para um mesmo texto, leituras podem ser possíveis numa época e não em outra e podem variar com o modo como são considerados os diferentes tipos de discurso. Já quanto à previsibilidade, a autora afirma que os sentidos têm sua história, ou seja, existe sedimentação em determinadas condições de produção. Também considera a necessidade de ter em conta a intertextualidade, ou seja, a relação com outros textos, que foram lidos antes, nas mesmas ou em outras condições de produção. 0 leitor tem sua história de leitura, um conjunto de leituras já feitas, que configuram, em parte, a compreensibilidade de cada leitor específico, noção que para ela se aproxima do que seria a "[...] capacidade de leitura" (idem, p. 9).

Em se tratando de leitura e pensando na possibilidade de mediação, lembramos que, na mesma obra, O rlandi comenta que

[...] o professor podemodificar as condições de produção da leitura do aluno: deum lado, propiciando-Ihequeconstruasua história deleituras; deoutro, estabelecendo, quando necessário, as relações intertextuais, resgatando a história dos sentidos do texto (idem, p. 8). 
A autora também se refere à necessidade de um compromisso que "[...] coloque a capacidade de linguagem na constituição da própria condição da espé cie, já que o homem não é isolável nem de seus produtos (cultura) nem da natureza" (O rlandi, 1988, p. 17) e que "[...] tomar a palavra é um ato social com todas as suas implicações: conflitos, reconhecimentos, relações de poder, constituição de identidades, etc." (idem). Além disso, a autora indica também a relação necessária entre o objeto, as técnicas, a metodologia e a teoria; e, pressuposta a tudo isso, uma concepção de linguagem. Já a noção de formação discursiva, segundo 0 rlandi, é "[...] o lugar da constituição do sentido e da identificação do sujeito. É nela que todo sujeito se reconhece (em sua relação consigo mesmo e com outros sujeitos) [...]" (1988, p. 58). Assim pensada, a formação discursiva é demarcada como " [...] aquilo quenuma formação ideológica dada (isto é, a partir de uma posição dada em uma conjuntura sócio-histórica dada) determina o que pode e deve ser dito" (ibidem). E, ainda no que se refere especificamente à leitura, cabe destacar a afirmação da autora de que "[...] a nossa vida intelectual está intimamente relacionada aos modos e efeitos de leitura de cada época e segmento social" (O rlandi, 1998, p. 8). Com essa noção de formação discursiva, compreende-se que a autora afirme que "[...] uma mesma palavra, na mesma língua, signifique diferentemente, dependendo da posição do sujeito em uma ou outra formação discursiva" (idem, p. 12).

E, voltando ao pressuposto da não transparência da linguagem, ressaltamos aqui que, assim considerada, esta, além de suporte do pensamento e instrumento de comunicação de informações, é o produto do trabalho dos homens em sociedade, ou seja, efeito de um processo histórico. Assim, não se pode assumir que haja uma relação direta entre palavras e coisas. Já quanto ao discurso, dada essa perspectiva para a linguagem, ele passa a ser constituído enquanto estrutura e acontecimento, ou seja, um processo social cuja especificidade está na sua materialidade linguística, e nele pode-se apreender a relação entre linguagem e ideologia, com a noção de sujeito como mediadora.

I deologia que, nessa vertente da $A D$, é considerada como aquilo que torna possível a relação entre palavras e coisas, a relação entre pensamento, linguagem e mundo. Assim pensada, ela não é ilusão, nem falsidade, nem ocultamento, nem dissimulação do real, nem tampouco visão de mundo. Segundo O rlandi (1999), um dos pontos fortes da AD é ter ressignificado a noção de ideologia, numa definição discursiva a partir da consideração da linguagem. Para a autora:

0 fato mesmo dainterpretação, ou melhor, o fato dequenão há sentido sem interpretação, atesta a presença da ideologia. N ão há sentido sem interpretação e, além disso, diantedequalquer objeto simbólico o homem élevado ainterpretar, colocando-se diante da questão: o queisto quer dizer? $\mathrm{N}$ essemovimento da 
interpretação o sentido aparece-nos como evidência, como se eleestivessejásemprelá. Interpreta-seeao mesmo tempo negasea interpretação, colocando-a no grau zero. $\mathrm{N}$ aturaliza-se 0 queéproduzido narelação do histórico edo simbólico. Por esse mecanismo - ideológico - deapagamento da interpretação, há transposição deformasmateriaisem outras, construindo-setransparências- como sea linguagem ea história não tivessem sua espessura, sua opacidade - para serem interpretadas por determinações históricas que se apresentam como imutáveis, naturalizadas. Esteéo trabalho da ideologia: produzir evidências, colocando o homem narelação imaginária com suas condições materiais deexistência(1999, p. 45-46).

Tendo em conta o papel da ideologia como entendido pela AD, ao pensarmos as condições de produção da leitura, além das condições imediatas, precisamos também considerar as condições de produção em sentido amplo, o que implica considerar relações com outros discursos que já foram produzidos antes e que têm, por sua vez, suas próprias condições de produção. Trata-se de ter em conta a memória discursiva, ou interdiscurso. De acordo com O rlandi, o interdiscurso:

[...] édefinido como aquilo quefalaantes, em outro lugar, independentemente. $\mathrm{O}$ u seja, é o que chamamos de memória discursiva: o saber discursivo quetornapossível todo o dizer eque retorna sob aforma do préconstruído, o já-dito queestánabase do dizível, sustentando cadatomada da palavra. 0 interdiscurso disponibiliza dizeresqueafetam o modo como o sujeito significa em uma situação discursiva dada (1999, p. 31).

O u ainda, segundo Pêcheux (1997, p. 77):

[...] tal discurso remeteatal outro, frenteao qual éuma resposta direta ou indireta, ou do qual ele "orquestra" os termos principais ou anula os argumentos. Em outros termos, o processo discursivo não tem, de direito, início: o discurso se conjuga sempre sobreum discurso prévio, ao qual eleatribui o papel de matéria-prima, eo orador sabeque, quando evoca tal acontecimento, quejá foi objeto do discurso, ressuscitano espírito dos ouvintes o discurso no qual este acontecimento era al egado, com as "deformações" que a situação presente introduz e da qual podetirar partido

Se pensarmos a leitura como um processo discursivo, tendo em conta essas noções, notamos que, nesse, como em outros processos discursivos, funcionam formações imaginárias; ou seja, está em jogo no processo um mecanismo que 
tranforma a situação em sua representação. Assim, na interação discursiva entre o leitor e o texto, não é possível desconsiderar a posição discursiva em que 0 leitor se insere aquela em que ele coloca seus interlocutores, os autores do que está lendo.

\section{D ispositivo analítico: articulação das noções teóricas}

Circunstanciar um dispositivo analítico de leituras, a partir das noções teóricas explicitadas no item anterior, implica interpelar, com essas noções, produções envolvendo diferentes tipos de discurso e analisar possíveis interpretações na leitura dessas produções.

N essa perspectiva, a textualização de determinado conteúdo num periódico científico ou num texto de divulgação científica evidencia formações discursivas bastante distintas, ainda que ambos se refiram ao mesmo tema. Q uando o cientista escreve para um periódico científico, ele o faz, tendo em vista os seus pares. Serve-se, portanto, da linguagem própria da formação discursiva em que o conteúdo a veicular foi produzido. Assim, se procurarmos ler um periódico científico atual da área de Física, certamente vamos notar que grande parte dos textos estarão redigidos em linguagem formal, a chamada linguagem da Física, a linguagem matemática. Já o jornalista ou o cientista que produz um texto de divulgação supõe a sua leitura por um público leigo, daí 0 uso frequente pelos autores do que consideram ser a linguagem cotidiana e de imagens, tendo em vista ser entendidos por seus leitores. Já num livro didático, quer este se destine ao ensino básico ou ao superior, como apontado pelo nome, os conteúdos são didatizados. $E$ nesse processo, aparentemente, a tentativa é de simplificação, tendo em vista o ensino escolarizado. M as, ao fazêlo, frequentemente os autores acabam descontextualizando os conhecimentos e apresentando-os como verdades a serem, muitas vezes, apenas decoradas para efeitos de avaliação.

Se, além disso, considerarmos a imagem que o leitor faz do autor do livro, não é difícil notar o poder de verdade e a suposição de ser destinado a poucos que 0 artigo científico pode exercer no imaginário de seu leitor. Isso, em alguma medida, é extravasado também para o livro didático, com os autores assumindo o papel do cientista, representação possivelmente reforçada pelo tipo de linguagem que o livro didático adota, usualmente com muitas definições e enquadramentos, resultados científicos cuja origem e cujos modos de produção não são explicitados.

M esmo quando o tema que está sendo tratado foi produzido há muito tempo, e sendo assim, no caso da Física, com um uso menor da linguagem matemática, as diferenças entre os tipos de textualização permanecem. Veja- 
mos, para exemplificar, o caso da lei da inércia atribuída a Galileu e que constitui a primeira das chamadas leis de $\mathrm{N}$ ewton. Este nasceu em 1642, na Inglaterra, e ali morreu em 1727. N a sua principal obra, o Principia, podemos encontrar a seguinte definição:

DEFINIÇÃO III

A força inata (ínsita) da matériaéum poder de resistir pelo qual cada corpo, enquanto depende dele, persevera em seu estado, seja de descanso, seja de movimento uniforme em linha reta (N ewton, 1974, p. 5)

Já no Livro III do sistema do mundo, N ewton apresenta seus Axiomas ou leis do movimento:
Lei I
Todo o corpo permaneceem seu estado de repouso ou de mo- vimento uniforme em linha reta, a menos que seja obrigado a mudar seu estado por forças impressas nele(idem, p. 14).

Vejamos o enunciado da lei da inércia num livro didático do início da segunda metade do século passado, destinado ao Ensino M édio:

U m ponto material, fora da ação de todo e qualquer agente físico, está, em relação a um sistema inercial, em repouso, ou realizaum movimento retilíneo uniforme (Rodrigues; Pieroni, 1957, p. 118).

O u o enunciado que pode ser encontrado num livro didático, também para o Ensino M édio, mas publicado em nosso século:

Todo corpo continua em seu estado de repouso ou de movimento retilíneo uniforme, a menos que seja obrigado a mudar esse estado por forças aplicadas sobre ele (Sampaio; C al çada, 2005, p.70)1.

$\mathrm{O}$, ainda, vejamos a lei da inércia como apresentada num dos principais livros didáticos destinados ao Ensino Superior, escrito por cientistas, entre os quais o vencedor do prêmio N obel, Richard Feynman. Depois de atribuírem a descoberta da lei a Galileu, eles escrevem:

[...] prinćpio deinércia: seum objeto for deixado sozinho, senão for perturbado, elecontinuaráa semover com velocidadecons-

1. Essa publicação corresponde a um do livros ado tados pelo Ministério da Educação no Programa N acional do Livro Didático para o Ensino Médio para os anos de 2009 a 2011. 
tanteem linhareta, seinicialmenteestavasemovendo, ou continuará parado seestava parado (Feynman et al., 1963, p. 9-1).

$\mathrm{E}$, por último, vejamos como é apresentada a lei num texto de divulgação científica. Referindo-se às leis newtonianas do movimento, o autor escreve: "Primeira lei de N ewton: todas as coisas permanecem em repouso ou se movem em linha reta na mesma velocidade, a não ser que uma força aja sobre elas" (Poskitt, 2001, p.157).

Apesar de produzidos em diferentes momentos, e certamente apresentando diferenças de formalidade na linguagem com que foram escritos, sendo que 0 último fala, inclusive, em "coisas", os enunciados aqui transcritos parecem não apresentar diferenças tão significativas. Entretanto, transcrevemos a seguir trechos do que os autores escreveram logo em seguida ao enunciado das leis. A presentamos um trecho para cada livro citado, mantendo a ordem em que apresentamos as leis:

Essa força ésempre proporcional a seu corpo, enão difereda inérciadamassa senão no nosso modo deconceber [...] (N ewton, 1974, p. 5).

N ão épossível comprovarmos diretamenteestalei, por não ser possível colocar um ponto material fora da ação de todo equalquer agentefísico [...] (Rodrigues; Pieroni, 1957, p. 118).

D essemodo, senenhuma força atua sobreum corpo, estando eleem repouso, deverá permanecer em repouso. Para queum corpo saia do repouso, devemos aplicar sobreeleumaforça. Se, depois de iniciado o movimento, retirarmos a força, o corpo deverá continuar em movimento retilíneo uniforme(Sampaio; Calçada, 2005, p. 70).

C ertamenteesse não parece ser o caso na natureza, pois seempurrarmos um bloco sobre uma mesa ele pára, masisso ocorre porque ele não é deixado só por si - ele está friccionando na mesa [...] (Feynman et al., 1963, p. 9-1).

Bem, a primeira parteda le ésimplíssima. Tudo quenão estáse movendo só vai semover sealguma coisalheder um empurrão. Fácil.

A segunda parteémais interessante. Dizquetodas as coisasque estão em movimento continuarão semovendo parasempreem linha reta na mesma velocidade, a não ser que uma força aja sobre elas. I magine que você esteja num carro, [...] (Poskitt, 2001, p. 157).

Podemos notar que, enquanto $\mathrm{N}$ ewton e os autores de livros didáticos aparentemente não mudam a linguagem, esta passa a ser altamente interativa no livro de divulgação científica, o que é uma das características comuns nesse 
tipo de texto, ainda que al gumas vezes em detrimento do rigor. 0 utra diferença significativa é o grande número de imagens explicativas que o livro escrito por Poskitt apresenta.

$\mathrm{N}$ as imagens apresentadas abaixo, 0 autor procura utilizar situações cotidianas em nossa sociedade, de forma a exemplificar a ação de forças. Ele recorre a imagens que representam situações de aceleração familiares aos estudantes. N 0 primeiro caso, um banco de automóvel e no segundo, uma montanha-russa:
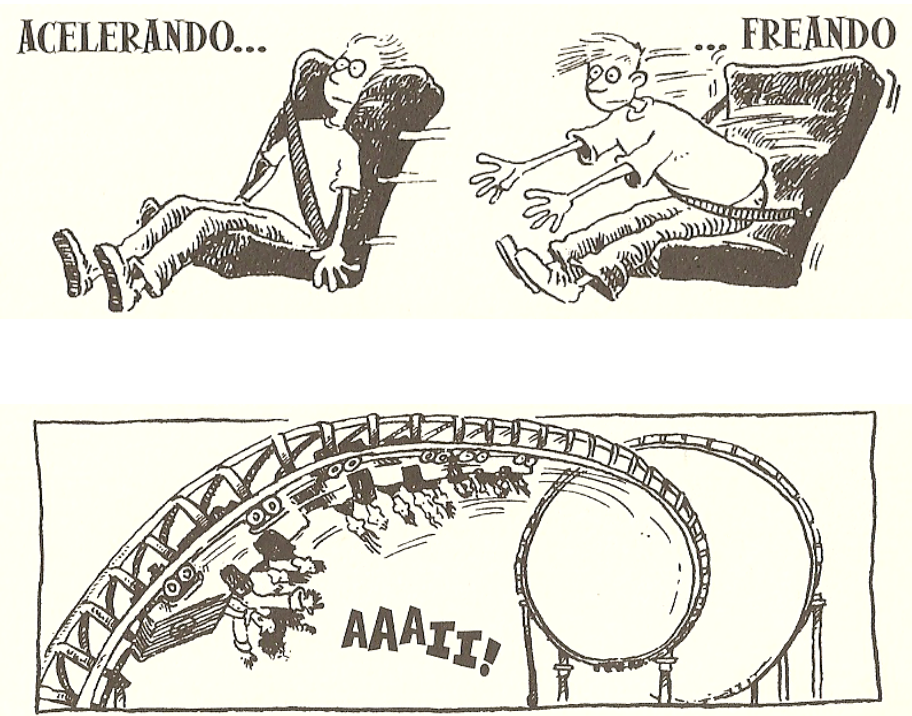

Figura 1: Poskitt, 2001, p. 145

É interessante notarmos que a linguagem utilizada nessas imagens também estabelece relações com um tipo de discurso normalmente comum no cotidiano dos jovens: a história em quadrinhos.

Essa mesma relação pode ser observada nas imagens a seguir, nas quais 0 autor procura explicar o movimento de "coisas" ao redor da Terra, utilizando extrapolações que, de forma criativa e engraçada, facilitam a compreensão do papel atribuído à força gravitacional e à resistência do ar. 

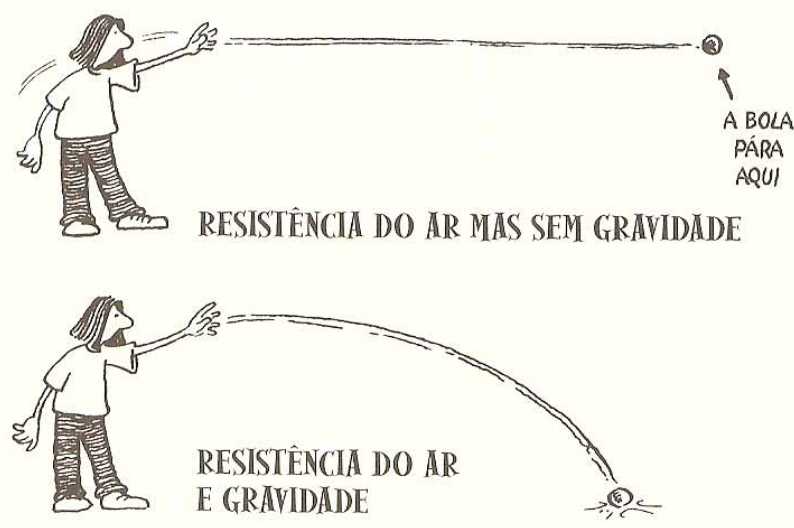

Não fossem essas forças, a bola voaria em linha reta sem parar até o fim do Universo!

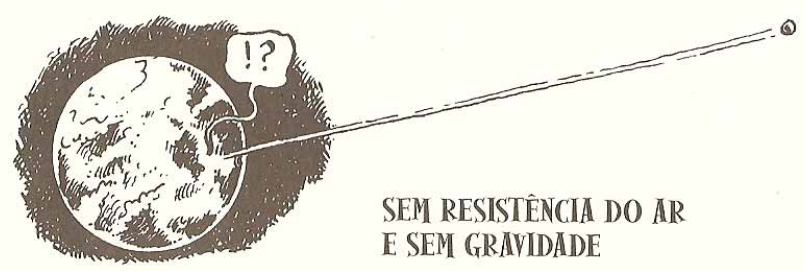

Essa é boa, hein?

Figura 2: Poskitt, 2001, p. 146

O livro didático também recorre a imagens, ao abordar as leis de N ewton, mas observamos, em algumas delas, apresentadas a seguir, que as relações que estabelecem são diferenciadas daquelas do livro de divulgação científica. N o caso do livro didático, também aparecem imagens; neste caso, fotos que procuram "retratar" situações também cotidianas. Já os desenhos, que são frequentes nos livros didáticos, não dialogam com os jovens, como as histórias em quadrinhos, e contêm elementos característicos das formalizações utilizadas na Física. 


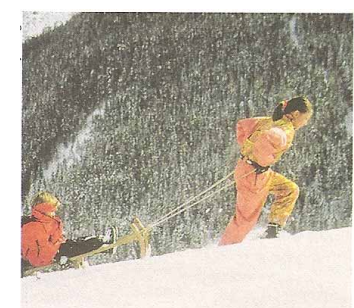

(a) Ao puxar o trenó, a menina exerce, através do fio, uma força $F$ sobre ele.

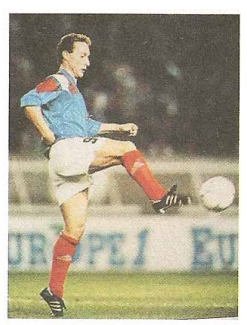

(b) Ao chutar a bola, o jogador exerce uma força F sobre ela.

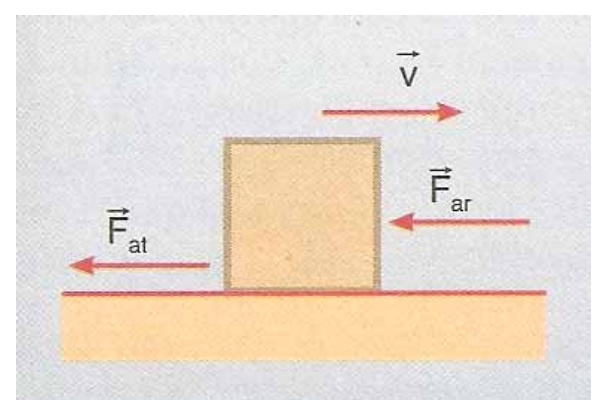

Figura 3: Sampaio e Calçada, 2005, p. 70-71

E, ainda, para evidenciarmos diferenças que uma ou outra textualização provoca no imaginário do leitor, podemos notar o poder que o livro didático exerce no ensino escolar, na transcrição da resposta de um aluno de Licenciatura em Física que já lecionava na escola básica. Q uestionado sobre como planejava suas aulas, ele disse: "Leio todo 0 assunto a ser dado. Procuro alguns assuntos 'fora' do livro didático para tornar a aula mais atrativa; às vezes planejo alguns experimentos".

D esse discurso podemos notar como, no imaginário desse licenciando, 0 livro didático não é atrativo para os seus alunos. M esmo assim, é aparentemente sua fonte principal para planejamento das aulas. 0 utras leituras ou experimentos são secundários. As representações do licenciando justificam-se, se pensarmos na sua história como estudante. É altamente provável que, na grande maioria das disciplinas que cursou na escola básica e na universidade, ele tenha estudado por livros didáticos ou por textos que os imitam. Sendo assim, é provável que, em seu imaginário, ensinar Física esteja bastante associado àquilo que usualmente se faz com um livro didático. 


\section{Algumas consequências}

As noções da $A D$ aqui apresentadas, quando articuladas como dispositivo analítico, evidenciam que as interpretações possíveis, ou seja, as produções de significados dependem de interdiscursos associados ao envolvimento com certas formações discursivas, mas também do contexto sócio-histórico e da história de vida do leitor, sem que ele próprio tenha total acesso à constituição de sua memória discursiva. Já as condições de produção imediatas, que podem contribuir para um ou outro direcionamento na produção dos significados, estão associadas tanto aos conteúdos quanto aos tipos de discurso veiculados. M uito do que aprendemos devemos à leitura; e um dispositivo analítico, ainda que oriundo da linguística, permite que pensemos situações de leituras em funcionamento no ensino escolar e na educação não formal das ciências da natureza.

Como consequência, podemos apontar alguns deslocamentos nos modos de propor e analisar leituras. Em primeiro lugar, ressaltamos a não expectativa de que elas produzam um único significado. Se, então, pensarmos na conveniência do acesso a muitos tipos de discursos para um mesmo conteúdo, essa nos parece uma perspectiva promissora para a educação. Um estudante que resista ao estudo por livros didáticos pode gostar de ler textos de divulgação científica. 0 aprendizado decorrente da leitura dos diferentes tipos textuais certamente não será o mesmo. M as, nos dois casos, provavelmente ocorrerão crescimentos culturais significativos.

0 dispositivo em funcionamento também nos alerta para um equívoco: a possível hierarquia entre diferentes linguagens no ensino. Isso ocorre, por exemplo, no ensino da Física, quando é proposto que se ensine determinado conteúdo primeiro conceitualmente (linguagem comum) e, só depois, as operações (linguagem matemática). Como alternativa, as duas modalidades podem caminhar paralelamente. $\mathrm{N}$ ão apenas por não ser possível uma tradução total de uma linguagem na outra (Almeida, 2004, p. 117), mas também por não conhecermos suficientemente as histórias de cada estudante e as consequentes conexões que ocorrerão em suas memórias discursivas na produção de significados.

\section{Referências bibliográficas}

ALM EID A, M . J. P. M . D iscursosda ciência e da escola: ideologiaeleituras possíveis. C ampinas: M ercado de Letras, 2004. 127p.

FEYN M AN, R. P.; LEIGHTON, R. B.; SAN DS, M .. The Feynman lectures on Physics. M assachusetts: Addison Wesley, 1963.

H ELLER, A. 0 cotidiano ea história. 2. ed. Rio de aneiro: Paz eTerra, 1985. 121p. 
N EWT O N , I. Princípios matemáticos da filosofia natural. São Paulo: Abril C ultural, 1974. 237p. (Coleção O spensadores).

O RLAN DI, E. P. A produção da leitura esuas condições. Leitura: Teoria ePrática, C ampinas, v. 2, n. 1, p. 20-25, abr. 1983.

O RLAN DI, E. P. Ashistórias das leituras. Leitura: Teoria ePrática, Campinas, v. 3, n. 3, p. 79, jul. 1984.

O RLAN DI, E. P. Discurso eleitura. São Paulo: Cortez, 1988. 100p.

O RLAN DI, E. P. Paráfraseepolissemia: afluidez nos limitesdo simbólico. Rua, Campinas, n. 4, p. 9-19, 1998.

O RLAN DI, E. P. Análisedediscurso: princípioseprocedimentos. Campinas: Pontes, 1999. 100p.

PÊCH EUX, M. Análise automática do discurso. In: GADET, F.; H AK, T. Por uma análise automática do discurso: uma introdução à obra de $M$ ichel Pêcheux. Campinas: Editora da U nicamp, 1997.

PO SKITT, K. Isaac N ewton esua maçã. São Paulo: Cia. das Letras, 2001. 192p.

RO D RIGU ES, E. C.; PIERO N I, R. R. Física 1. São Paulo: Clássico-Científica, 1957.

SAM PAIO , J. L.; CALÇAD A, C. S. Física. 2. ed. São Paulo: Atual, 2005. 472p. Volume único.

Recebido em 15 deoutubro de2010 eaprovado em 10 dedezembro de 2010. 
